\title{
Perversas latinoamericanas en el cine de terror: evolución y configuración de una cotidianidad transformadora, conflictual y decolonizante
}

\section{Rocío Pérez-Gañán'}

Resumen: Este artículo ha tratado de profundizar en el análisis de los arquetipos de mujeres perversas presentes en el cine de terror latinoamericano en comparación, por un lado, con las representaciones e imaginarios hegemónicos del cine "occidental" y en relación, por otro, con la (re)producción y retroalimentación de estos arquetipos perversos en la cotidianidad de sus respectivas sociedades. A través de un análisis fílmico se ha realizado un acercamiento al texto cinematográfico como documento sobre una cultura y como producto cultural o sociológico al mismo tiempo. De este modo, considerando el cine no solo como un elemento "reflector" sino como un elemento "configurador" de un orden moral, político y social determinado en un contexto histórico concreto, se han analizado las tensiones y las posibilidades de estas mujeres perversas de (re)presentar modelos alternativos que van a poner en duda, continuamente, las bases de la organización social y económica patriarcal centrada en la familia, en la propiedad privada y en el capital.

1 CONICET e Centro de Estudios de la Argentina Rural (CEAR) - Universidad Nacional de Quilmes (UNQ) - Bernal (Buenos Aires) - Argentina - rocio.ganan@unq.edu.ar. 
Palabras clave: Género; arquetipos femeninos perversos; cine de terror; decolonialidad.

\section{The Perverse Latin American Women of Terror Films: The Evolution and Con- figuration of a Transformative, Conflictual and Decolonizing Everyday Life}

Abstract: This article attempts to deepen the analysis of the archetypes of perverse women found in Latin American horror films in comparison, on the one hand, with the representations and hegemonic images of "Western" films, and, on the other hand, in relation to the (re)production and feedback of these perverse archetypes in the everyday world of their respective societies. By way of an analysis of the films, this paper approaches the cinematographic text as document about a culture as well as a cultural and sociological product. Thus, considering film, not just as a "reflecting" element, but also as a "configuring" element of a moral, political and social order in a concrete historical moment, I analyze the tensions and possibilities of these perverse women to (re)present alternative models that continually call into question the base of patriarchal social and economic organization centered on the family, private property, and capital.

Keywords: Gender; perverse female archetypes; horror films; decoloniality.

Más allá de un cine para ser mirado: caminando hacia un cine que observa, intersecciona y (re)construye

Tradicionalmente, en las teorías feministas que analizan el universo cinematográfico las representaciones de hombres y mujeres en el cine quedaban definidas por la posición de la mirada, por el lugar que esta ocupa (Mulvey, 2001). No obstante, a pesar de la relevancia de visibilizar este posicionamiento subordinado, estas teorías no ponían en entredicho que esta visión escondía una asignación esencialista en los términos dicotómicos hombre-mujer, analizando y adscribiendo comportamientos y conductas positivas o negativas según el rol de procedencia y el sujeto de destino negando, de este modo, la inclusión de sujetos que no se identificaban con ninguna de estas dos categorías. Asimismo, se homogeneizaba la participación de las mujeres en el proceso de comunicación, reduciendo el mismo a un proceso lineal de Emisión-Mensaje-Recepción donde la importancia queda totalmente concentrada en el mensaje y en el nivel del intercambio de mensaje, olvidando los procesos de producción (codificación) y recepción (decodificación) como procesos específicos de autonomía relativa 
dentro de la comunicación (Hall, 2004), adoleciendo, esta crítica feminista, de una interseccionalidad que cuestionase los procesos y la propia construcción política de la categoría "mujeres" más allá de espacios geográficos y lugares determinados (Haraway 1991; Lauretis, 1987).

$\mathrm{Al}$ ser el género una representación construida históricamente y en continua e incesante articulación a través de otras representaciones, significados, ideologías y discursos el cine se articulaba como una tecnología del género, una fuente de primer orden para indagar sobre su construcción y representación (Foucault, 1980). Con la incorporación de herramientas metodológicas de base semiótica a la teoría fílmica a principios de los años setenta, una parte de los estudios feministas -de producción estadounidense-europea, principalmente-, se dirigió hacia el análisis de películas como un texto en sí mismo desde una perspectiva estructuralista (Juha, 1994). La premisa principal era deconstruir el texto fílmico para revelar el funcionamiento ideológico del patriarcado, que convertía a la mujer en un mito, en un significante fijo. El desafío, para este análisis feminista se convertía así en la capacidad de mirar más allá del lenguaje fílmico y tratar de desenmascarar la elaboración de los significados construidos, la significación del film. De este modo, la premisa central para los análisis textuales realizados desde el feminismo ha tratado de detectar la existencia de funciones o interacciones recurrentes en los textos del cine clásico, y su relación con "la mujer", considerada ya no como un ser humano sexuado, sino como una estructura que gobierna la organización del argumento y la trama (Kuhn, 1985).

No obstante, un análisis semiótico no resulta suficiente para abordar la construcción y el significado de las mujeres en el cine. El texto audiovisual no se limita al sistema de comunicación o significación; analizarlo implica ir más allá. El reto del audiovisual reside en que no es únicamente "signo" visual, sino además imagen, que en su textualidad -no así en su discurso-, escapa al lenguaje y se refugia en la imaginación y el deseo. A la semiótica no le interesa el inconsciente, lo que no se puede explicar de forma consciente y lógica, pero esa intransigencia ignoró la dimensión simbólica en las cadenas de acciones propiamente narrativas. Sue Harper ha señalado el riesgo de no reparar en los aspectos extra-teóricos que subyacen a los sistemas de representación al mostrar que despojar a una imagen de su contexto implica invisibilizar los intereses y la ideología en la que se origina (Harper, 2000). En esta línea, Linda Williams (1988) señala la necesidad de que tanto los análisis feministas desde el psicoanálisis y la semiótica como los estudios desde la sociología, antropología y la historia deberían trabajar de una forma relacional para enriquecerse mutuamente. 
Todo producto cultural se genera en un contexto socio-histórico concreto, con valores, preferencias y perspectivas teóricas e ideológicas específicas. En este sentido, la antropología visual ha aportado un análisis complementario para la comprensión del texto audiovisual. Al considerar la imagen como un producto cultural y al analizar sus usos sociales y su aporte a la formación y transformación de identidades (Ardévol, 1998: 217-218) el acercamiento al estudio del texto cinematográfico se aborda desde un enfoque sistémico, donde al análisis textual se le añade un estudio contextual que integra los procesos de construcción cinematográfica y de la experiencia subjetiva del público espectador en la producción y reproducción de estereotipos y arquetipos. Asimismo, a partir de los estudios decoloniales² (Walsh, 2004; Escobar, 2003; Mignolo, 2003; Quijano, 2000; Chakrabarty, 2000; Castro-Gómez, 1998) resulta indispensable ampliar la mirada en el análisis fílmico e intentar revelar la relación estructural existente entre la producción visual y unas estructuras de poder global, que internalizan jerarquías específicas derivadas de la división internacional del trabajo, la patriarcalización, la racialización de la población y la economía mundial globalizada, ejes de la matriz colonial (Mignolo, 2003: 50). Lo interesante aquí reside en visibilizar que producto/proceso cinematográfico forma parte:

"[D]el aparato cultural del capitalismo avanzado, es decir, el hecho de que el cine en tanto medio, está atravesado por las relaciones mercantiles que afectan y conforman la industria cultural, siendo en sí mismo una empresa económica y lugar de reproducción ideológica de la cultura; el hecho de ser parte también de las formas artísticas del capitalismo avanzado, y en este sentido, el ser portador de estilo y singularidad, lugar de la expresión; por último, y de esta manera tensionada, el ser parte fundamental en la construcción de las subjetividades modernas, gran 'educador sentimental'”. (Millán, 1998: 150)

2 Los estudios decoloniales en los que se apoya este trabajo son fruto de los debates y las aportaciones del grupo de investigación "Proyecto latino/latinoamericano modernidad/colonialidad” (Escobar, 2003). El concepto 'decolonialidad' que este grupo de investigadores e investigadoras abordan parte del supuesto de que: "la división internacional del trabajo entre centros y periferias, así como la jerarquización étnico-racial de las poblaciones [...] no se transformó significativamente con el fin del colonialismo y la formación de los Estados-nación en la periferia" (Castro-Gómez y Grosfoguel, 2007: 13), sino que responde: “a una transición del colonialismo moderno a la colonialidad global, proceso que ciertamente ha transformado las formas de dominación desplegadas por la modernidad, pero no la estructura de las relaciones centro-periferia a escala mundial" (Ibídem). De este modo, resulta imprescindible visibilizar como el capitalismo global contemporáneo: "resignifica, en un formato posmoderno, las exclusiones provocadas por las jerarquías epistémicas, espirituales, raciales/étnicas y de género/sexualidad desplegadas por la modernidad" (Ibídem). 
A partir de estas consideraciones teóricas podemos observar el peligro latente que reside en la representación de arquetipos, como las mujeres perversas - en la producción cinematográfica -, que se alejen de la normatividad hegemónica establecida. Estos personajes femeninos poseen la capacidad de identificación, de alguna manera, con el público espectador. Son hermosas, inmortales, poderosas y logran atraer la atención de las espectadoras como protagonistas de la acción; por ello, al final, deben ser abatidas por las diferentes fuerzas de la normatividad (Flores, 2014; Lunich, 2012). Los actos que cometen las monstruas no pueden quedar impunes. Del mismo modo que la destrucción de la bruja se realizaba de forma ritual e intencionada, también se sigue toda una ceremonia para acabar con las perversas en el film. Cuando la mujer se rebela, se empodera y toma con(s)ciencia de sí misma, el protagonismo permitido debe ser encauzado de nuevo, a los brazos de la norma (López; Tierney, 2014, Villarreal, 2001). En este sentido, profundizar en los aspectos textuales (semiológicos) y extra-textuales (contexto y experiencia de la espectadora) como método principal de trabajo ha permitido una aproximación a la construcción del imaginario femenino desde diversos espacios de creación y representación. Asimismo, visibilizar las especificidades representativas de las mujeres perversas en el cine latinoamericano permitirá ampliar unas categorías de análisis que, la mayor parte de las veces, homogenizan las diversidades, supeditándola a una colonia$\operatorname{lidad}^{3}$ sucinta no solo en las formas de (re)producción cinematográfica sino en su aproximación y análisis.

Abordar un análisis fílmico no resultaba una tarea sencilla, siendo necesario realizar un acercamiento desde ángulos diferentes - pero interrelacionados -, para poder dar una visión holística del objeto estudiado. De este modo, se seleccionaron veinticinco películas para ser analizadas de producción latinoamericana y veinticinco películas realizadas en Europa y Estados Unidos ${ }^{4}$ donde los personajes femeninos perversos -las vampiras-, tuvieran cierto peso en la narración más allá del mero acompañamiento del personaje masculino principal.

Específicamente, se ha realizado un acercamiento al texto cinematográfico como documento que refleja una visión sobre una cultura (Worth, 1981: 74-84), añadiendo un factor más de complejidad: la aproximación al cine como producto cultural o sociológico, la relación entre la producción (emisión), el producto (mensaje) y audiencia (recepción) (Ardévol, 2004: 12). Finalmente, el hilo conductor y

3 Cuya matriz de poder define el lugar que la raza, la clase y el género articulan en la configuración del sistema de dominación y explotación capitalista euro-norteamericano.

4 Por motivos de extensión este artículo se desarrollará a través de los ejemplos de diez películas representativas. 
articulador de esta aproximación interdisciplinaria responde a un enfoque de género y decolonialidad ${ }^{5}$ que permitiera comprender la posición que ocupan las mujeres en el producto cinematográfico no solo cómo género, sino en un diálogo con la etnia/región geográfica de pertenencia y con la clase social en la que se inserta. En el marco de este proceso ${ }^{6}$, al mismo tiempo individual y colectivo, se ha tratado de mostrar cómo se articulan las representaciones de las mujeres perversas en el espacio fílmico y cómo, a su vez, estas representaciones son un reflejo y una retroalimentación en y del espacio social, respectivamente. Asimismo, dentro de este marco contextual se ha reflexionado en relación a la potencialidad de la representación de la mujer perversa (ejemplificada en la mujer vampiro) como un vehículo liberador para las mujeres, en el sentido de presentar diferentes opciones de elección y acción o, por el contrario, si trata de una construcción aleccionadora que ratifica que salirse de la norma sigue teniendo un castigo físico o social del que no es posible escapar.

\section{Evolucionamos con nuestras monstruas y ellas evolucionan con nosotras: de una amante en las sombras a una depredadora con conciencia de causa}

Para profundizar en las dimensiones del mito de la vampira, ha sido necesario realizar una triple desesencialización del mismo: en primer lugar como mito en sí mismo, en segundo lugar como el imaginario de mujer que construye y finalmente como la imagen de perversa que agrega. Para este ejercicio, el acercamiento al mito se ha realizado desde una concepción antropológica del mismo que responde a una existencia fenomenológica concreta en la sociedad. El mito es "una forma esencial de orientación, una forma de pensamiento, más aún, una forma de vida" (Van der Leeuw, 1940: 134), que ha pasado históricamente de una concepción de "contenido-teoría" a otra de "forma-estructura" de existencia con una "cuádruple intencionalidad: hierofánica, paradigmática, pancrónica e imaginativo-activa” (Cruz, 2007: 34).

El mito se refiere a la historia de los actos de seres sobrenaturales (intencionalidad hierofánica); esta historia, que es verdadera y sagrada, se refiere a una creación: cuenta cómo la totalidad de las cosas o una estructura de cosas

5 Añadiendo a la perspectiva de género la interseccionalidad raza y clase en el análisis fílmico.

6 Este artículo se apoya en la investigación: "Arquetipos femeninos perversos en el cine de terror: el mito y la construcción de la mujer vampiro y su (re)producción en la sociedad occidental" publicada en forma de libro en el año 2014 en España. A partir de un proyecto original que analizaba el mito de la mujer vampiro en el cine de producción norteamericana y europea se amplió la investigación para realizar un estudio comparado con el cine latinoamericano. 
se ha fundado como ejemplar de lo demás (intencionalidad paradigmática); en el mito se conoce el origen de las cosas: se trata de un conocimiento vivido - no meramente abstracto-, en el acto de narrar ceremonial o ritualmente el mito, de suerte que el tiempo débil de lo principiado se apoya y absorbe en el tiempo fuerte del origen (intencionalidad pancrónica); finalmente, las fuerzas páticas e imaginativas [...] tienen un papel preponderante en este fenómeno (intencionalidad imaginativo-activa). (Cruz, 2007: 34)

Es decir, a la construcción de lo sobrenatural (vampirismo) se le otorga un carácter sacralizado que lo fija a una inmutabilidad verdadera (vampirismo = maldad) y que posee una dimensión sincrónica que lo ancla al principio de los tiempos y lo legitima a partir de un conocimiento empírico originario que nadie puede refutar puesto que nadie puede volver al origen. De este modo, a pesar de que la experiencia subjetiva del ser humano puede (re)construir el mito difícilmente puede hacerlo fuera de la lógica de maldad atribuida en el caso del vampirismo. De la misma manera, los constructos específicos de mujer y perversa que se añaden al mito vampírico quedan impregnados de esta concepción esencialista que evoluciona superficialmente a (re)interpretaciones más adecuadas a las realidades que vivimos pero que, sin embargo, arrastra una carga de significación moral y de principios que garantiza la preservación del practicismo patriarcal y el cumplimiento de sus reglas. No obstante, la deconstrucción de esta forma-estructura del mito vampírico sí es posible y el cine es uno de los vehículos más potentes para ello. A partir de una representación continuada del mito donde existan grietas en esa verdad legítima y originaria la estructura del mito comenzará a quebrarse. Es decir, la representación de vampiras en el cine con personalidades complejas y comportamientos humanos, como veremos más adelante, van a permitir socavar este mito de la mujer vampira como mujer esencialmente perversa merecedora de castigo por salirse de su rol establecido.

En un acercamiento al cine de puede observarse una evolución que tanto hombres como mujeres presentan dos características comunes en todas sus representaciones en la gran pantalla: una carga erótica que tiene su origen en la novela Drácula (1897) de Bram Stoker y un uso de este monstruo o monstrua como representación de los miedos sociales y políticos de cada tiempo muy unida a la lógica de la modernidad etnocéntrica y su relación dialéctica con "el otro" (Quijano, 2000). Una o un "otro" que, sin embargo, va a presentar notorias especificidades. En el cine, de sus primeras representaciones como monstruos repulsivos (Nosferatu, 1922) las y los vampiros han evolucionado hacia la elegancia de la nobleza victoriana (Dracula’s Daughter, 1936) para convertirse, en 
los últimos años, en depredadores urbanos unas veces ocultos y otras viviendo como un ser humano más en las ciudades (Underword, 2003). De este modo, nuestras y nuestros monstruos han crecido junto a nosotros y nosotras. Han creado y recreado diacrónicamente los miedos de un mundo en continua ebullición, en incesable cambio (Pérez Agustí, 2005) así como la amenaza del "otro" ante la necesidad de definir lo que era y es euro-norteamericano y lo que no, lo que se inserta en el relato hegemónico de la modernidad ${ }^{7}$ lo que queda fuera. La folklorización y exotización de los Balcanes en películas como Nosferatu (1922) de F.W. Murnau (1922), El fantasma de la noche (1979) de Werner Herzog o Blood for Drácula (1974) de Paul Morrissey; el abandono del medio rural en Estados Unidos con su reflejo en los espacios agrarios desiertos de Near Dark, (1987); la "amenaza" feminista que se sugieren en Queen of the Damned (2001) donde la reina Akasha despierta de su letargo milenario, devora a su marido e intenta instaurar un matriarcado destruyendo a todos los varones tras ver la situación del mundo patriarcal actual; la búsqueda de la identidad unida a la soledad, el aislamiento y el anonimato en una ciudad vertiginosa y voraz a través de Kathleen, la joven protagonista de The Addiction (1995) o la agresividad y la pérdida de valores de las y los vampiros de John Carpenter’s Vampires (1998) son ejemplos de lo que Vesna Goldswothy describe como una forma de colonización por medio de la imaginación (Goldswothy, 2000, citado en Markuš, 2006: 3) una representación que, en este caso, va construyendo un imaginario de estos miedos unidos a la otredad y a la monstruosidad (Carrol, 1990; Boss, 1986; Brophy, 1986; Kristeva, 1982).

En América Latina, el cine de vampiros ha seguido, en un primer momento, una línea paralela a la euro-norteamericana como participante desde la periferia en este relato único de la modernidad aunque presenta elementos de una evolución propia que van a ir inscribiéndose paulatinamente en el marco de las reivindicaciones de una producción cinematográfica a nivel regional influenciada por las teorías de pensamiento postcolonial y decolonial y la búsqueda de una identidad propia:

La reivindicación de una identidad propia es intrínseca a lo anterior: sus films establecieron un diálogo con las tradiciones populares vernáculas al mismo tiempo que emprendieron una renovación de las formas cinematográficas en el subcontinente. En ese sentido, uno de los aspectos que caracteriza a estas

7 Se denomina a esta visión "eurocéntrica" porque "indica como punto de partida de la "Modernidad" fenómenos intra-europeos, y el desarrollo posterior no necesita más que Europa para explicar el proceso" (Dussel, 2000: 45). 
propuestas [...] es la negación del valor universal de los modelos estéticos eurocéntricos; así como la denuncia y posterior inversión de la lógica colono/ colonizado- civilizado/salvaje con que las potencias occidentales se aproximaban al llamado “Tercer Mundo". (Del Valle, 2014: 1)

La primera película de terror latinoamericana fue la versión mexicana de la película Drácula de Tod Browning (1931) filmada en español por George Melford. Durante este periodo era costumbre rodar una versión en español de las películas norteamericanas por las noches, para su distribución en América Latina. Este primer Drácula latinoamericano (cuyo actor, Carlos Villarías, era español) es representado como un depredador más despiadado y perverso que su homólogo americano Bela Lugosi. México está más lejos de ser Europa que los Balcanes y, además, es un país no desarrollado que hace frontera con Estados Unidos, por lo que esta distancia y la otredad que conforma debe ser más marcada, más amenazadora, más exótica, más salvaje (Markuš, 2006). A pesar de que el mito del vampiro va acompañado, desde el inicio del cine, de una sexualidad y una maldad explícita, en el caso del cine latinoamericano, esta sexualidad, fiereza y monstruosidad es más acentuada desde el comienzo, configurándose como un símbolo definidor de "la otredad" de América Latina. El éxito de esta cinta -que es señalada como inicio de la época dorada del cine fantástico mexicano, en concreto, del ciclo gótico mexicano-, va a posibilitar el rodaje de la primera película exclusivamente mexicana de género fantástico, La Llorona (1933), introduciendo otro elemento diferenciador con el cine norteamericano y europeo: elementos propios de horror basados en la cultura y el "folklor" (Martí, 1996: 25-29) local. De este modo, las y los monstruos cotidianos de la literatura y el cine (vampiros, brujas, hombres-lobo), se sincretizan con las tradiciones del lugar, no solo con tradiciones y leyendas externas, como el caso de Europa y Norteamérica donde, la mayoría de las veces, hay un hilo conector con la otredad balcánica. Aunque esta Llorona y las secuelas que propició (La herencia de la llorona, Mauricio Magdalena, 1946), no tiene demasiados elementos comunes con el vampirismo, comienza a afianzar el género de terror en el cine mexicano de las décadas de 1930 y 1940, donde se erige como el más prolífico y popular de habla hispana.

Libre del código Hays de producción cinematográfica en EEUU -y de la posterior Clasificación por edades de la $\mathrm{MPAA}^{8}$-, el cine mexicano pudo ofrecer junto a su folklor toda una serie de elementos argumentales tópicos del género

8 La Motion Picture Association of America (Asociación Cinematográfica de América). 
de terror e imágenes explícitas (vampiros aristócratas, concubinas vampiras, fiereza, erotismo, sexualidad, sangre a borbotones, hombres lobo, maldiciones ancestrales, sociedades secretas etc.) que el cine americano más comercial no podía (Rosas, 2003). Varios de estos elementos son visibles en films como El vampiro (1957) de Fernando Méndez y su secuela, El ataúd del vampiro (1958) en los que Méndez iba añadiendo, como un toque distintivo, elementos autóctonos que integraban a esta representación terrorífica el pasado colonial de la región: alejadas haciendas que sustituían los remotos castillos europeos, sirvientes con rasgos indígenas, etc. Es destacable en estos primeros films la presencia de mujeres vampiro antagonista que aunque están supeditadas al vampiro principal, son personajes con gran fuerza - como Eloísa, aliada del conde Lavud en el primer film, quien aspira a gobernar junto a él la región. A principios de los años 60 van a estrenarse un gran número de películas de vampiros en México donde ya se comienza a abandonar este vampirismo caracterizado por la presencia de familias aristocráticas, grandes haciendas lejanas, víctimas aisladas y, como se señalaba anteriormente, de herencia exclusiva del vampirismo balcánico en pos de una monstruosidad de alcance globalizado, pero de origen local o, al menos, en una combinación balcánico-local. Por ejemplo, en El mundo de los vampiros (1960) de Alfonso Corona Blake donde el vampiro Sutobai pretende acabar con la raza humana o el los films de Miguel Morayta La invasión de los vampiros (1961) y su secuela El vampiro sangriento (1962) en la que Brunilda, hija de un misterioso conde, sería la encargada de seguir con destino familiar de convertir a la humanidad en vampiros (aunque es salvada a tiempo del maleficio por el doctor protagonista. Con el film Santo contra las mujeres vampiro (1962) de Corona Blake va a iniciarse una línea de films en los que la mezcla de lucha, erotismo y cine de terror va a ser la marca característica mexicana, alejándose de los hieráticos y aristocráticos vampiros europeos. Producciones como Santo en el tesoro de Drácula (1968) de René Cardona, El vampiro y el sexo (1968), película polémica y censurada por su contenido erótico, Santo en la venganza de las mujeres vampiro de Federico Curiel (1970), Santo y Blue Demon contra Drácula y el hombre lobo (1973) de Miguel M. Delgado, o Los vampiros de Coyoacán (1973) de Arturo Martínez donde Superzán, Blue Ángel y el Fantasma Blanco se enfrentan a los vampiros que habitan en Coyoacán y que han matado a otro luchador.

Los vampiros mexicanos son expresivos, ruidosos, alborotadores, sensuales, asesinos y salvajes. Las mujeres, además, son frías, histéricas, sexuales y doblemente amenazantes: como monstruas y como mujeres fuera de los roles femeninos establecidos. 
[Condesa Mayra: Conocerás el éxtasis y morirás. Y así como yo me acerco a ti, tú te acercarás a mí. Y conocerás el éxtasis de la crueldad, que es otra forma de amor"]

Santo en la venganza de las mujeres vampiro, 1970.

[El conde Drácula: Ahora vayan a aplacar su sed de vampiras con sangre humana como debemos hacerlo todos los que estamos detenidos en el extraño puente que hay entre el final de la vida y el comienzo de la muerte [Todas las vampiras se desnudan, levantan sus abrazos y desaparecen entre gritos]]

El santo contra El vampiro y el sexo, 1968.

Estos vampiros y vampiras mexicanos - latinoamericanos por un ejercicio de extrapolación del colonialismo de la imaginación (Goldswothy, 2000) - son representados de forma distinta a sus homólogos europeos y norteamericanos quienes a pesar de ser también depredadores, mantienen un comportamiento racional, refinado, irónico y romántico que les va acercando paulatinamente más a lo humano.

[Lady Esme Hammond: Sherry, Marya?

Countess Marya Zaleska: Thank you, I never drink... wine.]

Dracula's Daughter, 1936.

[Count Von Krolock: I am a night bird. I am not much good in the daytime] Dance of the Vampires, 1967.

[Dracula: [to Paul] But you are. Before the castle was destroyed, strangers were always welcome. Please be seated. While your room is being prepared, you will take some wine?]

Scars of Dracula, 1970.

A finales de la década de los sesenta el cine mexicano comienza a resentirse, influenciado directamente por el impacto de las producciones en Estados Unidos, finalizando su "época dorada" con realizaciones de muy bajo presupuesto y calidad. Esto afectará de un modo especial a las películas de vampiros que experimentan un giro hacia historias donde sexualidad y violencia son los elementos que se entremezclan, sin demasiado desarrollo narrativo, en las que las vampiras son poco más que un producto para su fácil comercialización y consumo (Rosas, 2003). Es necesario llegar hasta mediados de los años setenta para encontrar mujeres protagonistas, perversas, con una trama elaborada en películas vampíricas, aunque no de vampiros, como Mary, Mary, Bloody Mary (1974) y Alucarda (1975), ambas de Juan López Moctezuma, películas filmadas en inglés 
para entrar en el mercado americano, en las que sangre, perversidad, frialdad y sexualidad (lesbianismo y bisexualidad), sin olvidar elementos tradicionales de la historia mexicana como los pasacalles, inundan el film desde el inicio.

[Greta: Mary, I love you.

[Mary: [Mary thrust her fist into Greta’s neck]]

Mary, Mary, Bloody Mary, 1974

De este modo, con menos censura, el cine de vampiros y vampiras mexicano fue configurándose como un espacio más "salvaje", étnico, sexual y monstruoso, erigiéndose como la representación de la exotización del "otro" de la región latinoamericana. Tras un vacío en la década de los ochenta, Guillermo del Toro revaloriza los films de vampiros en México con la cinta Cronos (1991), un elegante giro al vampirismo, en la que un extraño artefacto es capaz de proporcionar la vida eterna a su usuario a cambio de que este consiga sangre humana para su supervivencia. Pero, sin duda, el respaldo de la taquilla se lo llevó From Dusk till Dawn (Abierto hasta el amanecer) de Robert Rodríguez (1996), un espectáculo visual cargado de gamberrismo, diálogos vertiginosos y una de las escenas más recordadas del vampirismo femenino: el sensual baile de Satanico Pandemonium (Salma Hayek) con una serpiente subida a un escenario.

$\mathrm{Al}$ alejarse de la profusa producción mexicana, pueden encontrarse films de vampiros (masculinos) a partir de finales de los años sesenta en Brasil como Um sonho de vampiros de Iberê Cavalcanti (1969) donde un científico al morir se convierte en vampiro e intenta convertir a toda la gente del pueblo (este film rescata elementos de las tradiciones carnavalescas brasileñas) o Nosferatu no Brasil vídeo de veintiséis minutos grabado en super ocho de Ivan Cardoso (1971) que narra la historia de la llegada de Nosferatu a tierras brasileñas. Hasta 1987 con As Sete Vampiras - también de Ivan Cardoso -, no se encuentran películas de vampiros con protagonistas femeninas.

[Narrador: Da sua querida, da sua bela Nayara, já não existe mais nada humano.jAh!, triste desígnio Nayara. Agora ela está transformada em uma mulher demônio, sedenta de sangue. Do sangue daquele que um dia ela amou]

As Sete Vampiras, 1987

En Argentina, el primer film de vampiros fue Sangre de vírgenes, de Emilio Vieyra (1967) en una atmósfera victoriana-hacendataria de amor, celos y venganza, seguido después por cintas como La saga de los Drácula (1972) y La orgía nocturna de los vampiros de León Klimovsky, también de 1972. Posteriormente 
llegarían Estigma de terror de Jorge Carlos García (1974) y su secuela Spectrum voraz (2003) donde Andrea, la mujer protagonista, es poseída por un espectro vampírico que necesita ferozmente sangre humana.

[Priest: If you really find yourselves in trouble...

Female vampires: We beg of you. [The female vampires bit the Priest's neck]] La saga de los Drácula, 1973

Tras un salto de casi veinte años donde las y los vampiros argentinos han perdido los restos de su estética "victoriana-hacendataria" para convertirse en monstruos que se mimetizan con la sociedad humana, aparece en pantalla No muertos de Alexis Puig (2000) y, posteriormente, Nocturnos de Ariel Medina, Maximiliano Ricciardi y Leandro Vitillo (2008) en la que tres historias diferentes de vampiros se entrelazan en las noche de Buenos Aires y El día trajo la oscuridad de Martín Desalvo (2013), películas del cine actual donde las historias en relación al vampirismo se hacen más minimalistas, profundizando en lo psicológico de los personajes. Al margen de México, Brasil y Argentina como países con una producción cinematográfica profusa encontramos films de vampiras en Colombia, en el año 1982, donde se proyecta Pura sangre de Luis Ospina, film donde un anciano hacendado, como consecuencia de una extraña enfermedad, debe tomar sangre de infantes para poder seguir viviendo. En Chile, es necesario viajar hasta el año 2002 para ver una película de vampiros Sangre eterna de Jorge Olguín, donde la cultura gótica y los juegos de rol se entremezclan en una trama psicológica.

A pesar de que en el cine de vampiros latinoamericano las vampiras han seguido caminos similares a sus homólogas europeas y norteamericanas siendo muchas veces meras acompañantes o concubinas del vampiro principal, también puede observarse varias vampiras fuertes y poderosas dueñas de la trama como en Alucarda (1975) o Nocturnos (2008).

[Alucarda: We will make a deal and seal it with our blood. We will make them pay]

Alucarda, 1975

[Valeria: Vas a estar conmigo siempre, y lo que mejor, vas a poder traer a quien quieras. A quien vos quieras. Como yo, que te elegí a vos]

Nocturnos, 2008

Al ser, simultáneamente, el texto cinematográfico un documento que refleja una visión sobre una cultura (Worth, 1981) y un producto cultural o sociológico, 
el sistema patriarcal en el que se produce y, al mismo tiempo, reproduce permea casi la totalidad del género donde las monstruas son construidas desde los ojos masculinos para su consumo. No obstante, en un ejercicio de apropiación, las mujeres pueden identificarse con las libertades que de ellas se derivan (sexuales, sociales). En el cine de vampiras, identificarse con algunos elementos de las representaciones de las monstruas como vida eterna, libertad sexual, poder o belleza no parece difícil. No obstante, el problema radica en el precio que es necesario pagar para conseguirlo. La ostentación de poder por parte de una mujer termina, la mayor parte de las veces, con su destrucción, no sólo física, sino con la dominación de sus actos y de sus pensamientos: la anulación de su empoderamiento. Uno de los mejores ejemplos de esta anulación femenina es representado en el film Alucarda (1975), donde la protagonista, a pesar de poseer un gran poder, finalmente, es vencida (y destruida) como consecuencia de su amor (el giro, en este caso es que es amor hacia su amante femenina, no sobre un protagonista masculino). En Alucarda se abordan temas como el satanismo, el vampirismo, la posesión infernal, las orgías y el lesbianismo, todo en el marco de la religión. Fue una película controvertida y muy criticada tras su estreno a causa de la violencia explícita, las escenas sacrílegas y la perversidad en torno a la religión y la moral. Alucarda es una mujer poderosa, que desafía el orden establecido, en especial, al culto religioso alrededor del que se articula la película. Ella se erige como el máximo exponente de mujer castradora, con capacidad de destruir a todos los hombres y su sistema patriarcal. En las representaciones de las vampiras estas mujeres amenazantes son caracterizadas como frías, agresivas, histéricas, sexuales y destructivas constituyendo un peligro para el orden existente y colonizando el imaginario del público espectador con la amenaza de una existencia futura caótica si estas mujeres, finalmente, vencen. De este modo, es necesario, para reestablecer dicho orden y como ejercicio ejemplificador, destruirlas. No obstante, otras se libran como Mary en Mary, Mary, Bloody Mary (1974), quien incluso destruye a su amor romántico y continúa su existencia sin remordimientos.

[Inspector: [The inspector is talking to Mary about the murders and the person responsible without suspecting that she is the murderess] Sorry for your young man. It must be horrible for you. I hope you can erase it from your mind. What are your immediate plans? What will you do?

Mary: Probably travel for a while.

Inspector: I see.

Mary: Try to find a new place and start over] 
Este sin remordimientos es un tema recurrente en las películas de vampiras y que se aleja de otros géneros donde las mujeres son protagonistas de la trama. En este sentido, la acción perversa de las mujeres vampiro sin justificación, sin arrepentimiento, sin cargo de conciencia y sin remordimiento parece ser lo verdaderamente aterrador para un sistema patriarcal que ha situado a las mujeres en los roles de la responsabilidad, el cuidado, la preocupación y la culpa. Ante la ausencia de estos roles el espacio de ficción en el terror se erige como un ámbito de posibilidad de decolonizar, ahora, el imaginario femenino extrapolando esta maldad de las perversas hacia el espacio cotidiano en aras de preguntarse: ¿y si no cuido hoy y no me preocupo por ello?, ¿y si no me siento culpable por no ceder a sus demandas?, ¿y si no me responsabilizo de sacar todo el trabajo yo sola adelante?, ¿Y si digo no?

Extrapolando las ideas de Silvia Federici en su Calibán y la bruja (2013), la figura de la vampira, a semejanza de la bruja, se conforma en los films de terror como la "encarnación de un mundo de sujetos femeninos que el capitalismo no ha destruido: la hereje, la curandera, la esposa desobediente, la mujer que se anima a vivir sola, la mujer obeah que envenenaba la comida del amo e inspiraba a los esclavos a revelarse" (Federici, 2013: 22), la perversa, la dueña de su sexualidad, la que no es madre, la mujer que dice no. Estos sujetos femeninos perversos, aunque (re)presentados para el consumo capitalista-patriarcal, son arquetipos que presentan rupturas -especialmente a través de la subjetivad del público espectador- con los propios sistemas hegemónicos establecidos en sus respectivos tiempos y contextos tensionando las realidades de las que se nutren y en las que se insertan (Pérez-Gañán, 2014).

\section{Configuraciones, tensiones y reflejos entre el cine y la sociedad latinoamericana}

Aunque, a priori, la evolución de las y los vampiros tanto en las producciones norteamericanas-europeas y latinoamericanas caminan de forma paralela, en las últimas décadas América Latina y Europa se alejan de la tendencia del cine de vampiros estadounidense. Mientras las producciones de Hollywood apuestan por conflictos de impacto global entre razas de monstruos (Saga Underworld (2003-2017), Saga Crepúsculo (2008-2012)), las producciones europeas y latinoamericanas apuestan por historias más cotidianas de acercamiento a las y los monstruos como Låt den rätte komma in (2008), Nocturnos (2008), Only Lovers Left Alive (2013) o What We Do in the Shadows (2014) o El día trajo la oscuridad (2013) tomando un carácter más introvertido, analista y psicológico donde estas y estos monstruos se humanizan de una forma "diferente" a lo 
representado hegemónicamente, ${ }^{9}$ en una profunda búsqueda de sí mismos, de sus raíces e historias regionales (Salinas, 2012). En este sentido, es interesante señalar este autoreconocimiento del cine latinoamericano en relación con algunos movimientos que surgen en los años sesenta y setenta y que intentan establecer un "diálogo con las tradiciones vernáculas, al tiempo que iniciaban una renovación estética de los cines nacionales” (Del Valle, 2014: 1). Este acercamiento a lo propio en la producción cinematográfica se va a caracterizar por "la negación del valor universal de los modelos estéticos eurocéntricos" y una conciencia decolonial (con la influencia de Fanon), con la que "cineastas como Glauber Rocha y el grupo Cine Liberación denunciaron y resistieron la penetración cultural norteamericana y europea" (Del Valle, 2014: 1).

Los proyectos cinematográficos latinoamericanos de descolonización cultural, comúnmente englobados bajo el concepto de "Nuevo Cine Latinoamericano", desarrollaron estrategias subversivas de producción, distribución y exhibición que buscaron reestructurar los campos cinematográficos nacionales, en los cuales los films hollywoodenses y el cine de autor europeo tenían una posición hegemónica. Este proceso, que alcanza su mayor efervescencia a finales de los años sesenta, se acompaña de un apoyo explícito a los proyectos de revolución política latinoamericanistas, que los cineastas buscaron potenciar con sus obras. (Del Valle 2014: 1)

A pesar de que esta decolonización influenció notablemente las formas de producción cinematográfica de la región latinoamericana (con muchos matices según el país), el género de terror, articulado por unos elementos comunes y recurrentes de origen europeo, presentó una interesante apropiación y reconstrucción de la otredad. La introducción paulatina de la tradición y el folklor local (Martí, 1996) en las narraciones propició un camino para contar temores e historias propias que, si bien, no perdían del todo algunos matices coloniales, resignificó espacios, representaciones e identidades. De este modo, "lo monstruoso, como tropo de la 'otredad"' (Del Valle, 2014: 2) deja de compararse en relación a los discursos hegemónicos, se abraza y se reapropia, abandonando la "estigmatización de lo distinto que encierran los conceptos de monstruo y de monstruosidad" (Del Valle, 2014: 2). Lo monstruoso es parte de nuestra cotidianidad, y, lejos de idealizar y (re)crear lugares "perfectos", nos acerca mucho más a nuestra humanidad imperfecta, contradictoria y que

9 Donde se acepta, generalmente, el vampirismo y se utiliza el poder que conlleva para hacer "el bien", "el mal" o "vivir lo mejor posible con el monstruo" en un espacio amplio (ciudad, región, mundo). 
tratamos de negar. Así, lo monstruoso se reconfigura como un elemento cotidiano subversivo, de resistencia a lo hegemónico, a la normatividad, a lo impuesto; una reivindicación por ser diferente y actuar diferente. En este sentido, el cine de terror se articula como un espacio privilegiado para mostrar esta resistencia a un orden obligado, a una moralidad importada, a un comportamiento adecuado al que añade un guiño a través de la sobrenaturalidad que incorpora y que sirve como fisura del sistema y, a la vez, como artificio para escapar hacia una desobediencia normativa.

Sin embargo, dentro de estas transformaciones en Europa y Norteamérica y en la configuración del pensamiento decolonizador en América Latina (Salinas, 2012), es necesario señalar la posición que ocupa el género y, específicamente, las representaciones femeninas perversas en la gran pantalla. Así, resulta imprescindible resaltar algunos matices en este camino paralelo de vampiros y vampiras. En realidad, el análisis fílmico ha mostrado cómo nuestras vampiras han sufrido una evolución menos distinguida que sus homólogos masculinos tanto en Europa y Norteamérica como en Latinoamérica. Desde los inicios del cine mudo (un poco más tarde en los films latinoamericanos) ellas siempre han sido monstruas, pero también siempre han sido hermosas y con una carga especial de sexualidad explícita. En la mayor parte de las producciones son vampiresas, no vampiras (monstruas que además de su "intrínseca" maldad, poseen una sexualidad irresistible y consiguen su deseos a través la seducción) que acechan a sus víctimas en la oscuridad o en lugares recónditos, fuera del espacio cotidiano y normalizado. Ser una vampira no es lo mismo que ser un vampiro. Aunque lo monstruoso siempre ha sido "lo otro", lo ajeno, lo amenazante; la mujer, recreada como monstrua representa esa alteridad a la que añade la suya propia, una alteridad de género: la monstruosidad dentro de la monstruosidad. Barbara Creed ha creado una categoría para caracterizar a estas monstruas a la que denomina "lo monstruoso femenino", ya que su género es un componente más importante que su monstruosidad (a diferencia de los monstruos de sexo masculino), donde su presencia no significa necesariamente que tengan una implicación o liberación feminista (Creed, 1993: 7).

No obstante, algunas veces, la vampira sí se conforma, dentro de esta clasificación de "monstruosidad femenina" como monstrua-feminista, debido a su alternatividad como modelo femenino y a su impacto y retroalimentación en el espacio social. Las vampiras se resisten a la normalidad que es impuesta a las mujeres: los lugares donde se las sitúa, los roles que desempeñan, los comportamientos que desarrollan. Cuando el público espectador observa a Valeria, la vampira protagonista de una de las tres historias de Nocturnos (2008), tener 
una conversación en una fiesta nocturna donde expresa abiertamente lo que quiere del hombre con quien está hablando, este público está viendo otra forma de interacción mujer-hombre de la que suele ver en el cine o incluso en muchos ámbitos de su vida cotidiana. Una forma de interacción que, por supuesto, existe, pero que por los roles tradicionalmente asignados va a variar notablemente respecto a las experiencias de las personas que están visionando el film. Cada experiencia va a absorber esta conversación de una forma diferente, pero al invertir los roles, al producir un choque con la normalidad resulta difícil que produzca indiferencia. De esta manera se produce una brecha, una fisura, un modelo diferente. Una monstrua-feminista:

[Román: ¿Qué tomás?

Valeria: Lo que quiero.

Román: $Y$, ¿qué querés?

Valeria: A vos te quiero.

Román: Es una joda. Sos amiga de Martín y me están haciendo una joda. Valeria: Soy la jefa de Martín.

Román: Yo soy el compañero de Martín. Te invito a una cerveza.

Valeria: Por ahora tengo todo lo que quiero.

Román: ¿Nos vemos en otro momento? Así me das tu teléfono.

Valeria: Yo estoy acá ahora. En otro momento no sé.]

Nocturnos, 2008

La fuerza de esta conversación no pasa desapercibida. Rompe varios roles de género: la mujer expresa su deseo sexual a un hombre directamente que quiere como pareja sexual, es lo que desea, es activa. La mujer es la jefa de un hombre y le señala a otro su error al posicionarla, antes de conocerla, como su compañera de trabajo. La mujer tiene la autoridad en la conversación, es la que marca el encuentro y la que deja claro el momento en el que se debe dar. No obstante, aún existen pocos ejemplos de mujeres perversas en los films de vampiras que tengan tanta fuerza y capacidad de acción y que no sean destruidas física o socialmente tanto en las producciones europeas-norteamericanas como en las latinoamericanas.

[Alucarda: ¡Belphegor! ¡Belcebú! [Alucarda hace estallar en llamas a las monjas del convento. Se separa de Daniela, su amante, quien resulta herida por ladestrucción que ella a desencadenado. Pierde el control y empieza a girar sobre sí misma en la capilla hasta que se desvanece a los pies de un Jesucristo crucificado en llamas] 
[M: [M entra en la casa de los vampiros y dispara repetidas veces a Carmila, su antigua pareja, ahora convertida en vampira]]

Sangre eterna, 2002

Aunque el cine latinoamericano ha avanzado mucho en la reescritura de sus propias historias fuera de una historización eurocéntrica a través de sus propias voces "que proponen contra-verdades, contra-narrativas que son parte de una perspectiva anticolonialista" (Shohat; Stam, 2002: 251), en la mayoría de las ocasiones, este compromiso político se olvida del género, por un objetivo mayor, ratificando, una vez más, el orden patriarcal establecido. La transgresión en el cine latinoamericano es mayoritariamente política, intelectual y cultural, pero no tanto de género. Sin embargo, y a pesar de todo, todo cambia, y las perversas del cine no son una excepción. En una secuencia cronológica puede apreciarse que, así como el vampiro va adquiriendo "nobleza" a lo largo de sus representaciones cinematográficas, la vampira clásica, salvo algunas excepciones, va relegando su protagonismo fílmico a saciar pasiones, propias y ajenas. Tan solo en las últimas décadas parecen recuperar, estas perversas, un espacio fuera de esta sexualidad para el consumo masculino. No obstante, su monstruosidad-feminista va a verse determinada por el elemento "normativizador" por excelencia: el amor. Un amor patriarcal que pretende ser una vía de control a la libertad de estas mujeres perversas. Por ejemplo, en Sangre de vírgenes (1967) Ofelia no puede vivir con la carga de ser una vampira y haber perdido a su amor, pide ayuda al protagonista (al que seduce) pero acaba suicidándose para liberarse.

[Hombre: ¿Quién eres?

Vampira Ofelia: Un ser condenado. Me ha sido negada la dicha en la vida y la paz en la tumba. Pero tú puedes salvarme

Hombre: ¿Salvarte de qué?

Vampira Ofelia: Del horror de vivir en la muerte. Sálvame, te lo ruego]

Sangre de vírgenes, 1967.

Afortunadamente, algunas vampiras escapan a este amor normativizador proponiendo otras formas de amar como Anabel en El día trajo la oscuridad (2013) quien escoge como compañera a Julia, la otra protagonista de la historia o como Valeria en Nocturnos (2008) quien propone un ejercicio de poliamor.

[Valeria: Vas a estar conmigo siempre, y lo que mejor, vas a poder traer a quien quieras. A quien vos quieras. Como yo, que te elegí a vos] 
En las producciones latinoamericanas contemporáneas las vampiras protagonizan historias cotidianas en las que la dicotomía humano-monstrua se desdibuja, por un lado, humanizando a la monstrua y, por otro, demonizando a la humana, saliendo de los espacios normativos en los que se insertan las mujeres e interpelando al público espectador en aras de reconocer subjetivamente esta monstruosidad. Las vampiras han empezado a aceptar la parte perversa como algo propio, una parte de su (re)existencia, tenga el coste que tenga. Bajo el (re)planteamiento del concepto maldad como un mecanismo más de control normativo, ser malvada resulta peligroso. Esta maldad desafía la moral y los principios patriarcales en los que las mujeres deben cumplir una serie de requisitos para entrar en el club de "las buenas esposas, las abnegadas madres y las voluntariosas cuidadoras". Si las mujeres comienzan a ver reflejado más a menudo en la pantalla estos modelos de perversas -que ya son más humanas que monstruas- transgrediendo los términos de esta estructura de dominación (Bourdieu, 1998), por la sociedad de la imagen en la que nos encontramos podría erigirse como un vehículo importante para quebrantar los cimientos de dicha estructura (Ardévol, 2004).

En este espacio representado y consumido por el público espectador existe un lugar para la perversa, una perversa social que encarnará una determinación a seguir su propio camino frente a los deseos y necesidades del hombre. Estos nuevos modelos femeninos asumen la libertad sexual con fuerza. El amplio abanico de perversas discurre entre una multitud de mujeres sexuales, frías, ambiciosas, crueles, femeninas hasta el extremo o ambiguamente viriles, según las ocasiones (como Mary en Mary, Mary, Bloody Mary, 1975).

La perversa tampoco nace, se hace, y curiosamente, se construye rechazando sus roles asignados como mujer. Quizás sea esto lo más aterrador, que las mujeres sustituyan sus "motivos" para ser malas y los sustituyan por una actuación fuera de la moralidad atribuida a su condición femenina, sin valores, sin justificación, sin conciencia y sin responsabilidad, al igual que la monstrua de la gran pantalla. De este modo, las mujeres pueden identificarse con las perversas del cine ya que: "las buenas películas de monstruos son las que plantean la hipótesis de que todos, de alguna manera, llevamos al monstruo dentro de nosotros" (Benítez, 1995: 23). Esta monstrua que las espectadoras (y espectadores) pueden ver reflejada en la gran pantalla es aquella que actúa fuera de la moralidad atribuida a su condición femenina, sin valores, sin justificación, sin conciencia y sin responsabilidad. Y esto, es lo que resulta verdaderamente aterrador (Pérez-Gañán, 2014). 


\section{Conclusiones}

A lo largo de este artículo se de analizar cómo el imaginario de las mujeres perversas en el cine latinoamericano de vampiros ha sido resignificado desde su origen hasta los films más actuales y los efectos de esa resignificación. Los resultados de este estudio han mostrado que estas transformaciones se reflejan, entre otras cosas, en un proceso de empoderamiento fílmico que está posibilitando que las mujeres aparezcan, en algunos casos, como protagonistas y heroínas de una narrativa tradicionalmente reservada a los hombres. No obstante, la forma de considerar ese empoderamiento plantea cuestiones en las que es necesario profundizar ya que, en numerosas ocasiones, este protagonismo femenino tiene un alto coste para las perversas derivando en una destrucción física o social. De este modo, ha sido necesario conocer si el mito de la mujer vampiro cumple estrictamente una función moral y pedagógica de los cuentos populares y otras narrativas de ficción de tal manera que la mujer no pueda hallar en este mito un vehículo liberador sino, por el contrario, opresor, en la medida en que la trama termina castigándola por empoderarse y asumir un papel protagonista.

Siguiendo la línea de lo anteriormente expuesto, el arquetipo de mujer perversa en su representación vampírica se ha mostrado a lo largo del análisis fílmico como un factor con dos dimensiones opuestas que se entremezclan en diferentes grados y niveles permitiendo a las mujeres, por un lado, "recuperar" fragmentos de modelos femeninos alejados de las representaciones normalizadas mientras que, por otro, les advierte de las consecuencias que tiene seguir estos modelos fuera de la norma. Es aquí cuando la experiencia subjetiva de cada espectadora (y cada espectador) va a jugar un papel protagonista. Complementando el visionado de modelos femeninos que se alejan de los arquetipos tradicionales en el cine en el espacio de la imaginación del público espectador se va a (re)construir un imaginario en el que las vampiras van a posibilitar un modelo diferente. Estos modelos, a pesar de tener severos castigos, van a trasmitir ideas que van a ser (re)pensadas no solo en el marco de la ficción cinematográfica, sino en el contexto de las realidades cotidianas.

Es, en esta cotidianeidad, donde la actuación de las vampiras va a poner en duda continuamente las bases de la organización social y económica patriarcal centrada en la familia y en la propiedad privada. La libertad de pensamiento y la autonomía de acción femenina -especialmente en el control de su sexualidad y (re)producción- son una amenaza evidente para los sistemas capitalistas y el mantenimiento del preciado status quo. Si las mujeres comienzan a alejarse de sus modelos de referencia femeninos tradicionales, ¿quiénes van a soportar el 
peso de la producción y reproducción en el hogar? Por eso sigue siendo necesario castigarlas, mostrar que ese camino de libertad y decisión es mucho menos cómodo y agradecido que los beneficios que se reciben siguiendo los designios del amor, la responsabilidad y los cuidados. Sin embargo, en el contexto de un mundo donde la lucha de las mujeres ha dejado (y sigue dejando) una huella incuestionable, la incorporación de estos nuevos registros femeninos a la gran pantalla responde a una demanda imposible de ignorar. Si el más "macho" de los héroes cinematográficos ha tenido que ir acostumbrándose a compartir protagonismo con mujeres que piensan por cuenta propia, que siguen sus propios caminos o bien solucionan sus propios problemas, ¿cómo no va a hacerlo el espectador que consume estos modelos representados y, por ende, cómo no va a hacerlo la espectadora?

No sólo nuestras monstruas evolucionan con nosotras sino que nosotras evolucionamos con ellas. Aunque en el desarrollo de la(s) historia(s) y el movimiento de las mujeres los logros han sido múltiples y evidentes, esos cambios enmascaraban, en muchas ocasiones, una apariencia de realidad. Las mujeres han alcanzado una igualdad de forma en diferentes lugares, pero aún arrastran una subordinación histórica interiorizada que impide una igualdad real: las mujeres han accedido al trabajo, pero es necesario preguntarse en qué condiciones y en qué puestos; han conseguido una libertad de acción, pero a cambio de un precio en forma de tiempo, de energía y según comienza a verse, de salud, porque acceder al estatus de igualdad ahora pasa por ser una supermujer y hacer todo lo tradicionalmente "femenino", añadir lo "masculino" y no olvidar estar perfecta para cada ocasión.

Ante esta situación, las mujeres pueden empezar a plantearse que el coste de ser una mujer perfecta ha comenzado a ser mucho mayor que el de ser una mujer perversa. Ellas nos muestran que existen más opciones, que existe un derecho a reivindicar ser lo que se quiera ser, incluso si la elección es ser "malvada o egoísta”, aunque ser malvada no signifique más (y a su vez signifique tanto) que abandonarse a un placer sin medida, razón ni remordimiento en el film o no sentirse culpable al decir no a un rol impuesto de madre o cuidadora en la vida real. Asimismo, si realizan el ejercicio de deconstrucción de esta perversidad, se encontrarán con que ser malvada (en el sentido de romper con los roles tradicionales establecidos) las acerca mucho más a un verdadero estatus de igualdad. Por esto las perversas son necesarias. Ellas nos aproximan a realidades más justas, nos guían hacia un verdadero empoderamiento y una toma de conciencia del ejercicio de ese poder. Ellas son las perfectas para enseñarnos a decir no. 


\section{Referências}

ARDÉVOL, Elisenda (coord.). Representación y cultura audiovisual en la sociedad contemporánea. Barcelona: Universitat Oberta de Catalunya, 2004.

. Por una antropología de la mirada: etnografía, representación y construcción de datos audiovisuales. Revista de Dialectología y Tradiciones Populares del CSIC, V. 3, n.2, 1998, pp. 217-240.

BENÍTEZ, José Manuel. La vida imaginaria. Valencia: La Mirada, 1995.

BOSS, Pete. Vile Bodies and Bad Medicine. Screen, vol. 27, n. 1, 1986, pp. 14-24.

BOURDIEU, Pierre. La dominación masculina. Barcelona, Anagrama, 1998.

BROPHY, Philip. Horrality - The Textuality Of Contemporary Horror Films. Reprinted in Screen, vol. 27, n. 1, 1986, pp. 2-13.

CARROL, Noël. The Philososphy of Horror or Paradoxes of the Heart. New York $y$ London: Routledge, 1990.

CASTRO-GÓMEZ, Santiago. Latinoamericanismo, modernidad, globalización. Prolegómenos a una crítica poscolonial de la razón. In CASTRO-GÓMEZ, Santiago and MENDIETA, Eduardo (eds.). Teorías sin disciplina. Latinoamericanismo, poscolonialidad y globalización en debate. México: Grupo Editorial Miguel Ángel Porrua, 1998, pp. 169-205.

CASTRO-GÓMEZ, Santiago; GROSFOGUEL, Ramón. Prólogo. Giro decolonial, teoría crítica y pensamiento heterárquico. In CASTRO-GÓMEZ, Santiago; GROSFOGUEL (eds.). El giro decolonial. Reflexiones para una diversidad epistémica más allá del capitalismo global. Bogotá: Siglo del hombre editores, 2007, pp. 9-24.

CHAKRABARTY, Dipesh. Provincializing Europe. Postcolonial Thought and Historical Difference. Princeton: Princeton University Press, 2000.

CHATTERJEE, Partha. Our Modernity. Dakar-Rotterdam: Codesria-Sephis, 1997.

CREED, Barbara. The Monstrous-Feminine: Film, Feminism, Psychoanalysis (Popular Fictions Series). London: Routledge, 1993.

CRUZ, Juan. Sentido antropológico del mito. Anuario Filosófico, n. 4, 2007, pp. 31-84.

DE LAURETIS, Teresa. Technologies of Gender, Bloomington: Indiana University Press, 1987.

DEL VALLE, Ignacio. El monstruo colonizador y el monstruo liberado en la obra de Glauber Rocha y del Grupo Cine Liberación. Amerika, n. 11, 2014. Disponible en: $<$ http://amerika.revues.org/5473>. Consultado el 14 de febrero de 2017.

DUSSEL, Enrique. Europa, modernidad y eurocentrismo. In LANDER, Edgardo (ed.). La colonialidad del saber: eurocentrismo y ciencias sociales. Buenos Aires: CLACSO, 2000, pp. 41-53.

ESCOBAR, Arturo. Mundos y conocimientos de otro modo. El programa de investigación de modernidad/colonialidad latinoamericano. Tabula Rasa, n.1, 2003, pp. 51-86. 
FEDERICI, Silvia. Calibán y la bruja. Mujeres, cuerpo y acumulación originaria. Madrid, Traficantes de sueños, 2013.

FLORES, Silvana. Mujeres emergentes en el cine político latinoamericano: los cortometrajes de Sara Gómez. Cinémas d'Amérique latine, n. 22, 2014, pp. 48-56.

FOUCAULT, Michelle. Estética, ética y hermenéutica. Obras esenciales, Volumen III, Barcelona: Paidós Ibérica, 1999.

_. La microfísica del poder. Madrid, La Piqueta, 1980.

GLANTZ, Margo. La metamorfosis del vampiro, Biblioteca virtual Miguel de Cervantes, s/n, 2006, (1980). Disponible en: <http://www.biblioteca.org.ar/libros/134256.pdf >. Consultado el 15 de febrero de 2017.

HALL, Stuart. Codificación y decodificación en el discurso televisivo. CIC: Cuadernos de información y comunicación, n. 9, 2004, pp. 210-236.

HARAWAY, Donna. Ciencia, cyborgs y mujeres. La reinvención de la naturaleza. Madrid: Ediciones Cátedra, 1995 (1991).

HARPER, Sue. An Argument for Visual Anthropology. London: Falmer Press, 2000.

IADEVITO, Paula. Teorías de género y cine. Un aporte a los estudios de la representación. Universitas Humanística, n. 78, 2014, pp. 211-237.

JUHA, Alexandra. Nuestros autocuerpos, nosotras mismas: la re-presentación de las mujeres reales en el video feminista. Afterimage, v. 21, n. 7, 1994 pp. 10-14.

KRISTEVA, Julie. Powers of Horror: An Essay on Abjection. New York: Columbia University Press, 1982.

KUHN, Annette. The Power of the Image: Essays on Representation and Sexuality. Routledge: London, 1985.

LÓPEZ, Ana M.; TIERNEY, Dolores. IN FOCUS: Latin American Film Research in the Twenty-First Century. Cinema Journal, v. 54, n.1, 2014, pp. 112-142.

LUNICH, Ana Laura. Representación y revolución en el cine latinoamericano del período clásico-industrial: Argentina, Brasil, México. Avances de Investigación, n. 73, 2012, pp. 1-227. Disponible en: <http://www.fundacioncarolina.es/wp-content/uploads/2014/o8/ AI73.pdf $>$. Consultado el 15 de febrero de 2017.

MARKUŠ, Saša. Drácula: el monstruo balcánico en el cine europeo. Comunicación en Mostra Internacional de Cinema Europeu Contemporani, Barcelona, 2006. Disponible en: <http://www.ocec.eu/pdf/ 2006/markus_sasa.pdf >. Consultado el 25 de mayo de 2017.

MARTÍ, Josep. El Folklorismo. Uso y abuso de la tradición. Barcelona: Ronsel, 1996.

MIGNOLO, Walter. Cambiando las éticas y las políticas del conocimiento: lógica de la colonialidad y postcolonialidad imperial. Tabula Rasa, n. 3, 2003, pp. 47-72.

MILLÁN, Márgara. Feminismo(s) y teorías del cine: de la deconstrucción a la politización de las diferencias. Versión, n. 8, 1998, pp. 145-160. 
MULVEY, Laura. Placer visual y cine narrativo. In WALLIS, Brian. (ed.) Arte después de la modernidad: Nuevos planteamientos en torno a la representación. Madrid: Akal, 2001, 365-377.

PAYÁN, Miguel. Los cien mejores filmes de vampiros. Madrid: Cacitel, 2005.

PÉREZ AGUSTÍ, Adolfo. Cine de vampiros. Madrid: Masters, 2005.

PÉREZ-GAÑÁN, Rocío. Arquetipos femeninos perversos en el cine de terror. El mito y la construcción de la mujer vampiro y su (re)producción en la sociedad occidental. Santander: Universidad de Cantabria, 2014.

QUIJANO, Aníbal. Colonialidad del poder, eurocentrismo y América Latina. In: LANDER, Edgardo. (ed.) La colonialidad del saber: eurocentrismo y ciencias sociales. Perspectivas latinoamericanas. Buenos Aires: Clacso, 2000, pp. 201-245.

ROSAS, Saúl. El cine de horror en México. México D.F.: Saga ediciones, 2003.

SALINAS, Claudio. Colonialidad, Modernidad y representación en el cine latinoamericano contemporáneo. De Memorias del subdesarrollo a Pizza, Birra, Faso. AISTHESIS, n. 51, 2012, pp. 125-140.

SHOHAT, Ella; STAM, Robert. Multiculturalismo, cine y medios de comunicación. Crítica del pensamiento eurocéntrico. Barcelona: Paidós, 2002.

VAN DER LEEUW, Gerardus. L'homme primitif et la religión. París: Alean, 1940.

VANEE, Carole (comp.) Placer y peligro. Madrid: Revolución, 1989 (1984).

VILLARREAL, Magdalena. Reseña de "Cine y género: La representación social de lo femenino y lo masculino en el cine mexicano y venezolano" de Patricia Torres San Martín. Revista de Estudios de Género. La ventana, n. 14, 2001, pp. 344-348.

WALSH, Catherine. Introducción. (Re)pensamiento crítico y (de)colonialidad. In WALSH, Catherine. Pensamiento crítico y matriz (de)colonial. Reflexiones latinoamericanas. Quito, Universidad Andina Simón Bolívar-Abya Yala, 2004, pp.13-35.

WORTH, Sol. A Semiotic of Ethnographic Film. Philadelphia: Uviversity of Pennsylvania Press, 1981.

Recebido em 16/02/2016

Aprovado em 22/11/2016

\section{Como citar este artigo:}

PÉREZ-GAÑÁN, Rocío. Perversas latinoamericanas en el cine de terror: evolución y configuración de una cotidianidad transformadora, conflictual y decolonizante. Contemporânea - Revista de Sociologia da UFSCar, v. 7, n. 1, jan.- jun. 2017, pp. 167-191. 